\title{
Is the use of life history and narrative in clinical practice reimbursable? Is it occupational therapy?
}

Janice P. Burke

Thomas Jefferson University

Stephen B. Kern

Thomas Jefferson University

Follow this and additional works at: https://jdc.jefferson.edu/otfp

Part of the Occupational Therapy Commons

Let us know how access to this document benefits you

\section{Recommended Citation}

Burke, Janice P. and Kern, Stephen B., "Is the use of life history and narrative in clinical practice reimbursable? Is it occupational therapy?" (1996). Department of Occupational Therapy Faculty Papers. Paper 40.

https://jdc.jefferson.edu/otfp/40

This Article is brought to you for free and open access by the Jefferson Digital Commons. The Jefferson Digital Commons is a service of Thomas Jefferson University's Center for Teaching and Learning (CTL). The Commons is a showcase for Jefferson books and journals, peer-reviewed scholarly publications, unique historical collections from the University archives, and teaching tools. The Jefferson Digital Commons allows researchers and interested readers anywhere in the world to learn about and keep up to date with Jefferson scholarship. This article has been accepted for inclusion in Department of Occupational Therapy Faculty Papers by an authorized administrator of the Jefferson Digital Commons. For more information, please contact: JeffersonDigitalCommons@jefferson.edu. 


\section{THE ISSUE IS}

\section{Is the Use of Life History and Narrative in Clinical Practice Reimbursable? Is It Occupational Therapy?}

$\mathrm{N}$ arrative and life history methods in occupational therapy offer practitioners an opportunity to understand what might otherwise remain an unspoken and informal part of therapeutic interacrion. In contrast to the formal information about a patient's medical and psychosocial condition, therapists often gain insight into the patient's inner life (e.g., family background, favorite music, holiday and birthday traditions) through the spontaneous conversations that arise during trearment. This informal information is important to occupational therapists because it fills in the details about the pacients they are working with and how the illness experience is affecting, and will ultimately affect, the patients' lives. Informally collected data invariably find their way into treatment interventions, informing the selection of treatment goals, activities, and outcomes.

The use of factors such as age, roles, values, culture, and incerests to guide therapy has been a consistent theme in occupational therapy theories and frames of references (Miller \& Walker, 1993) and has been demonstrated as a strategy therapists use to form ideas during the treatment process (Clark, 1993; Crepeau, 1991; Matcingly \& Fleming, 1994; Peloquin, 1990). The use of case stories in the occupational therapy literature illustrate the central role of patients' scories in therapists' clinical reasoning (Clark, 1993; Crepeau, 1991; Martingly \& Fleming, 1994). The following is a description of such reasoning:

Since functional performance requires intention, physical action, and social meaning it is not surprising that people who concern themselves with enabling
Janice Posatery Burke, Stephen B. Kern

Janice Posatery Burke, MA, OTRL, FAOTA, is Assistant Professor, Department of

Occupational Therapy, College of Allied Health Sciences, Thomas Jefferson

University, 130 South 9th Street, Edison 820, Philadelphia, Pennsylvania 19107.

Stephen B. Kern, MS, OTRI, is Chief, Occupational Therapy Section.

Department of Rehabilitation Medicine, Thomas Jefferson University Hospital;

Clinical Assistant Professor, Department of Occupational Therapy, College of Allied Health Sciences, Thomas Jefferson University; and Consultant, Medicare Claims Review and Provider Assessment, Independence Blue Cross, Philadelphia, Pennsylvania.

This article was accepted for publication December 1, 1995.

function have to address problems of the person's sense of self, sense of future, physical body, meaning, and social and cultural contexts in which actions are taken and meanings are made. Since these areas of inquiry are typically guided by different rypes of thinking, it is necessary that therapists become facile in thinking about different aspects of humans using various styles of reasoning. Thus, putting it all together for the whole person to function as a new self in the fucure is guided by complex and multiple forms of clinical teasoning. (Fleming, 1993, pp. 879-880)

Narrative and life history methods provide a language to define how therapists interact with patients, come to understand the complexicy of the thera- peutic issues at hand, and decide to deal with those issues in therapy. Terms such as life world, illness experience, and the patient's story are examples of this language. By putting these ideas into words, therapists are able to frame the problems they are seeing in clinical encounters and begin to generate treatment interventions to address them. The language of these methods also gives therapists a way to share their ideas about what is going on with a particular patient as they informally interact with their occupational therapy colleagues. In addicion to influencing successful treatment ourcomes in occupational therapy, life history and narrative merhods also provide a way for therapists to discuss specific patient-centered issues with the family, members of the treatment team, and other professionals.

\section{The Occupational Therapy Process}

At each juncture of the occuparional therapy process, narrative and life history data can provide the therapist with foundational information. The data can guide insight and fuel decisions regarding issues of evaluation, goal serting and treatment planning, and discharge.

\section{Evaluation}

In considering occupational therapy's inherent commitment to occuparion, Clark and Larson (1993) strongly endorsed evaluation methods that allow the therapist to come to know the patienc:

\footnotetext{
.. of utmost concern to therapists would be evoking personal narratives from their patients that reveal the meaning the patient derives from particular occupa-
} 
tions, how they chunk or enfold their occupations, and how their occupational parterns flowing through the stream of time fit into a framework of how they understand theit lives... Therapisrs would also need to see illness and carascrophic injury not as isolated circumstances, but rather as a discontinuiry within a framework of a cotal life (p. 55).

Occupational therapists use formal and informal assessments as their primary modes of inquiry: "Who is this person?" For example, formal assessments, such as the Occupational Performance History Interview (Kielhofner, Henry, \& Walens, 1989), or informal assessments, such as the unstructured interview (Florey \& Michelman, 1982), yield information about the patient, including his or her roles and skills, cultural and personal values, sense and use of time, personal responsibilities, and perceptions of self. Pursing topics in conversarion, such as how parients spend their time, what they think they are good at, how they cope with everyday stressors, and what they hope to accomplish in the next year, can be highly useful in uncovering themes of meaning within the patient's life history. With this rype of informarion, therapists can identify the problems facing the patient and develop plans that will shape future treatment.

\section{Goal Setting and Treatment Planning}

In a discussion of the philosophical base of occuparional therapy, Yerxa (1979) presented an analysis of Eleanor Clarke Slagle lectures "to identify the values contained within them" (p. 27).

Focusing on values regarding patient-therapist interaction and the profession, Yerxa highlighted the role of the patient's perspective in the construction of therapeutic goals:

Occupational rherapy's use of 'meaningful' and 'purposeful' activity places value upon the parient's view of meaning... the meaning of the acrivicy, its choice, and sacisfaccion in it are derermined by rhe individual parient's needs, incereses and morivacions. (p. 27)

In a later work, Yerxa (1980) considered the fit between the health care "climate" (p. 529) of the furure and occupational therapy's "early mission of caring" (p. 529), stressing the importance of "a 'mutual cooperation' model of therapist-patient relationship, in which the parient and therapist enter into a partnership" (p. 532). Implementation of such values requires that the therapist come to know the patient and the unique concerns that are most important to that patient.

Because of reduced lengths of hospital stays, a therapist may ask, "How can I use the narrative method when I have so little time?" We believe that these circumstances only magnify the urgency to know the person in order to more efficiently prioritize goals, reevaluare goals during trearment, and lay the foundations for discharge planning. In today's inparient serrings, it is common for occupational therapists to see patients as litcle as one time before they are transferred to the next setting or level of care. In many instances, the first occupational therapist to see the patient is faced with making decisions that will determine the type and frequency of occuparional therapy services to be delivered at each succeeding health care juncture (e.g., home health care, outpatient services, communiry-based care). Similarly, in a school serring, the therapist may have only one session in which to evaluare a child before moving into a consultative role with the teacher to implement the occupational therapy treatment plan. This system of triaging occuparional therapy services has only recently emerged as a role and responsibility for therapists (Burke \& Cassidy, 1991). The use of narrative and life history methods to come to know and understand a patient's goals facilitates the coordination and delivery of care that can be given in health care's fast-paced climate.

\section{Treatment}

Narrative and life history methods are useful to both therapists and patients during treatment. While implementing treatment procedures, such as dressing and grooming training or fabricating a splint, a therapist can talk with the patient to determine the pattern of the patient's life before the injury or illness and how the patient foresees the impact of the illness or injury on his or her future life. When the therapist works with a person with a new disability, narrative and life history methods serve as opportunities to address occupational therapy-relaced concerns. For example, during a splint fitting, the patient may talk about how awkward visiting hours with relatives are. The therapist may take this opportuniry to provide input on behaviors the patient might use to reduce some of the emotional discomfort and isolation that is felt during family visits, for example, using whatever ice-breaking strategies he or she used before the disability when the interaction becomes awkward. Additionally, when a patient is performing activities that have been adapted to promote success, the therapist may take the opportunity to ask the parient to reflect on where else in his or her routines these current modifications or adaptations may prove useful. Thus, the patient is encouraged to reflect on his or her life roles, rourines, and responsibilities and to evaluate the effectiveness of an adaptation in promoting his or her own meaningful occupation.

\section{Discharge}

Guided by the parient's goals for resuming occupational roles, narrative and life history methods can help therapists plan for realistic and innovative patterns of continuing care and discharge. In health care, the increased emphasis on managed care, competition, and accountability as well as shrinking resources (e.g., time, personnel, money) are forcing us to look at what we do and how our services influence functional outcomes (occupational performance). Beyond checklists, observations, and traditional evaluations, assessments that provide a personalized view of patients within the context of their lives (e.g., family members, available resources, strengths, needs) will also provide the most effective mechanism for framing evaluation findings and the most realistic baselines and goals.

\section{A Refocusing on Occupational Therapy Concerns}

Among the key questions that will be 
voiced by our colleagues after reading last month's issue of the American Joumal of Occupational Therapy (AJOT, 50[4]) devoted to the topic of narrative and life history in clinical practice are:

(a) Is it really occupational therapy? and (b) Is it reimbursable? Given shrinking hospital and rehabilitarion stays, is there enough time to use these merhods? How will these approaches help treatment?

\section{Is It Really Occupational Therapy?}

Perhaps one of the most frequent reasons for dismissing the use of narrative and life history approaches is that occupational therapisss see these merhods as separate and different from those they use regularly in their work, something that must be added to their role as occupational therapists racher than being a natural part of their role. For example, occupational therapisss specializing in physical disabilities may be more concerned with the parient's actual physical deficits than with his or her personally defined deficits and needs. These therapisss' visions of the parient's problems may exclude the need to consider the parient's story, believing that it will keep the therapist from the work that must be done (as dictated by the specific physical deficits that are present with physical disability). Similarly, occupational therapy students and new therapists may also see narrative and life history approaches as burdensome, particularly if they have limited opportunities to develop the necessary patient interaction and psychosocial treatment skills.

The rherapists in each of these examples have lost sight of their professional education and training and are delivering a fragmented therapy where only physical aspects of care are addressed. These therapists have forgotten that they are able to create treatment environments that are uniquely constructed to meet a complex array of patient needs. In addirion, they are neglecting the importance of enlisting the patient's motivation in the therapy process. To evoke motivation, the therapist must turn to information gathered with narrative and life history methods to ensure that the patient will be an acrive parricipant in his or her recovery. From our observacion, when therapists seek to deliver patient-centered therapy, their concern with narrative and life history methods is much more evident.

\section{Is It Reimbursable?}

In discussing the use of therapeutic strategies, why do the treatment methods and modalities used to achieve goals become the focus of concern? In our experience, what is reimbursable is actual patient progress toward occuparional performance outcomes, not specific discrete behaviors such as increased strength and range of morion. Without providing a real-life context (an understanding of how a discrere behavior firs in to the life roles of the patient), progress is meaningless to a reimburser. For example, documenting that a man is able to lift 20 lb on Monday, April 12, and $25 \mathrm{lb}$ on Monday, April 19, is not demonstrating significant progress. What matters is that the conrext (the parient's job) requires that he is able to lift $25 \mathrm{lb}$ repeatedly and that because of occupational therapy treatment, he is now ready to fulfill his job duties.

A woman who has a lower extremity amputarion secondary ro arterioscleroric cardiovascular disease (ASCVD) is standing in therapy for $20 \mathrm{~min}$. The patient has minimal responsibilities at home and participates in occupations such as doing crossword puzzles, watching game shows, and socializing with farmily members and neighbors. She has nor been ambulatory for 5 years because of her ASCVD condirion and history of poor cardiovascular response to standing activities. Before her current treatment, the only standing she did was to perform transfers (e.g., moving from chair to bed). Within the conrexr of her life, we can see that the patient never stood for more than $5 \mathrm{~min}$ at a time. But this parient's occupational therapist has not addressed her occupational hiscory. The therapist has developed a treatment regimen based on her knowledge of the condition being treated; thus, she is continuing to work on improving the patient's standing tolerance as her occupational therapy program. To most insurer's, this therapy is not reimbursable without a documented link to what the patient will be able ro, or is able to do, in reallife settings as a resulc of therapeutic intervention. Again, what is missing in this patient's program is an understanding of the context (the occuparional performance) for the therapy and the objecrive and measurable outcome.

\section{Is There Enough Time?}

If narrative and life history methods are going to be thought of as in addition to routine therapy services, then no, there is not enough time during treatment to add anorher demand. As it is, some therapists are finding rhemselves barely able to evaluate, treat, and plan for discharge within the narrow specificarions of roday's healch care system.

If therapists are willing to reconceprualize their practices and consider these methods as a natural part of therapy, then yes, there is time. Our point here is that occupational therapists can creace opportunities for patients to provide important decails about their lives as they were before their accident or injury, the birth of their ill child, or the onset of their debilitating illness and as they hope to be when they complete therapy. By weaving this type of talking and thinking with the doing part of therapy, occupational therapisss are able to concentrate their own artention on questions about the disease or disability from the vantage point of funcrional problems and how the effects of those difficulties can be reduced. This kind of complex mulridimensional reasoning (i.e., considering questions of who parients are and what their lives will be now that they have a certain disease or injury) is not only commonplace but also essential to the occupational therapy process. The use of narrarive and life hiscory method is not a matter of it taking more or less time, it is a matter of being the essence of practice.

\section{How Will It Help Treatment?}

As suggesred previously, narrative and life history mechods are not done in 
addition to therapy. They are part of therapy - the lenses that are used to elicit information about a patient to establish appropriare and realistic goals, facilitare the collaborative relarionship between the therapist and patient, and keep the therapy focused on outcomes that are important and meaningful to the patient, caregivers, and family members. Therapeutic methods that help us design the most effecrive and efficient care seem to be particularly appropriate given the demands for high-quality, affordable, and cost-effective occupational therapy within the current climate of limited time, limited resources, shortages of therapists, and defensive posturing. The current movement in the health care environment of the 1990s is forcing us to get back to the heart of occupational therapy. It is time for us to give up the extraneous activities that others on the trearment team can do more inexpensively and begin to understand where our expercise is most effectively and affordably used. For example, in self-care training where occuparional therapists evaluate, establish, and monitor the appropriate dressing techniques and methods for training (reaching the new rechnique, modifying the environment, fabricating a new piece of equipment), aides and assistants provide the actual rourine tasks needed to establish and reinforce the skills.

\section{Summary}

Narrative and life history methods are deeply embedded in the occupational therapy process. The recent interest in and attention to these methods provide an opportunity for therapists to examine their routine practices and beliefs and consider some of the areas of patient practices that may have eroded over time. If we are to call ourselves occupational therapists, then our commitment to persons and the value that they place on activities and occupations must remain foremost in our minds. The strategies endorsed in last month's special issue of AJOT appear to be closely aligned to our goal of helping persons reach their valued occupational performance.

\section{Postscript}

In the months since this article was completed, changes in the delivery of occupation therapy services have been further influenced by managed care practice, which has resulted in conrinued currailment of parient services, including shortened lengths of hospital stays and limited therapy sessions. In response to these practice restraints, occupational therapists have experienced greater pressure to prioricize their therapeutic interventions. The use of methods such as narrative and life history are in greater jeopardy of being omitted as therapists question the relarionship of these methods to the funcrional ourcomes that are stressed by third-party reimbursers.

It is our belief that authentic occupational therapy requires the use of narrative and life history methods as part of occupational therapy practice. The challenge for our profession is to fit these methods into the lexicon of funcrional and physically measurable change. Hence, each therapist must accept the responsibility for ensuring that methods such as narrarive and life history are preserved regardless of the environments they find themselves in and that the data gathered from using these methods are talked about and documented in useful, outcomes-driven, consumer-oriented packages.

\section{References}

Burke, J. P., \& Cassidy, J. C. (1991). The Issue Is--Disparity berween reimbursement driven practice and humanistic values of occupational therapy. American Joumal of Occupational Therapy, 45, 173-176.

Clark, F. (1993). Occuparion embedded in a real life: Interweaving occupational science and occupational therapy. 1993 Eleanor Clarke Slagle Lecture. American Joumal of Occupational Therapy, 47, 1067-1078.

Clark, F., \& Larson, E. (1993). Developing an academic discipline: The science of occupation. In H. Hopkins \& $\mathrm{H}$. Smich (Eds.), Willard and Spackman's occupational therapy (8th ed., pp. 44-57). Philadelphia: Lippincott.

Crepeau, E. B. (1991). Achieving intersubjective understanding: Examples from an occupational therapy treatment session. American Joumal of Occupational Therapy, 45, 1016-1025.

Fleming, M. H. (1993). Aspecrs of clinical reasoning in occupational therapy. In $\mathrm{H}$. Hopkins \& H. Smich (Eds.), Willard and Spackman's occupational therapy (8th ed., pp. 867-881). Philadelphia: Lippincort.

Florey, L. L., \& Michelman, S. M. (1982). Occuparional role hiscory: A screening tool for psychiatric occupational therapy. American Journal of Occupational Therapy, 36, 301-308.

Kielhofner, G., Henry, A., \& Walens, D. (1989). A user's guide to the occupational performance history interview. Rockville, MD: American Occupacional Therapy Association.

Marcingly, C., \& Fleming, M. (1994). Clinical reasoning. Forms of inauiry in a therapeutic practice. Philadelphia: F. A. Davis.

Miller, R. ]., \& Walker, K. F. (1993). Perspectives on theory for the practice of occupational therapy. Gaithersburg, MD: Aspen.

Peloquin, S. M. (1990). The parient-therapist relarionship in occupational therapy: Understanding visions and images. American Journal of Occupational Therapy, 44, 13-21.

Yerxa, E. J. (1979). The philosophical base of occuparional therapy. In Occupational therapy: 2001 AD (pp. 26-30). Rockville, MD: American Occupational Therapy Association.

Yerxa, E. J. (1980). Occuparional therapy's role in creating a future climare of caring. American Joumal of Occupational Therapy, 34, 529-534. 